DOI 10.37882/2500-3682.2021.05.05

\title{
ПИЛОТНОЕ ИССЛЕДОВАНИЕ УРОВНЕЙ СОЦИАЛЬНО-ЛИЧНОСТНОГО РАЗВИТИЯ У ДОШКОЛЬНИКОВ В ТЕАТРАЛЬНОЙ СТУДИИ
}

\section{PILOT STUDY OF THE LEVELS OF SOCIAL AND PERSONAL DEVELOPMENT IN PRESCHOOL CHILDREN IN A THEATER STUDIO}

\author{
S. Batueva \\ Ya. Zhakupova \\ O. Gerasimova \\ L. Semchenko
}

Summary: The article reveals and empirically confirms the influence of the theater studio on the levels of social and personal development of preschool children. The components of social and personal development of preschool children are defined: motivational-emotional, communicativecognitive, and activity-creative. The personal qualities corresponding to each component are selected as criteria, and the descriptive characteristics of the selected qualities are given. The article presents the results of a psychological study of preschool children and their levels of formation of social and personal qualities ( $n=197$, average age $5.9 \pm 0.9$ years) who attend the theater studio in the Palace of Pioneers and Schoolchildren named after N. K. Krupskaya in Chelyabinsk; the children's theater studio of the MOE "SOSH No. 8» in Troitsk; the city House of Culture and art schools No. 1, No. 3 in Troitsk; the children's theater studio in Yuzhnouralsk. The paper considers the components of the criteria of social and personal development in preschool children and the methods of their diagnosis. Psychodiagnostic methods of research were used: the Rosenzweig test (1948), the Leopold and Sonya Bellac children's apperceptive test (SAT-N) (1966). Methods of studying the willpower readiness of the Bourdon test; methods of diagnosing creativity of Gilfrd and Torrens (1962); methods of diagnosing the level of development of an arbitrary sphere by N.I. Gutkina (1981); projective methods of diagnosing the nature of relations by T.D. Mirzinkovskaya (1997). The results of the ascertaining experiment are presented. At the stage of the ascertaining experiment, the results of the study of the levels of social and personal development in preschool children in two groups: those who attend and those who do not attend a theater studio are considered. The analysis of the quantitative results obtained at the stage of the ascertaining experiment is carried out. The results of the formative experiment are presented on the example of four groups: preschoolers did not participate in the activities of the children's theater studio; the activities of the children's theater studio were carried out according to the usual program; in the second experimental group, the design of the activities of the children's theater studio was carried out partially; in the third experimental group, the design of the activities of the children's theater studio was carried out in full. The article considers the dynamics of social and personal development of preschool children in the activities of a children's theater studio using dynamic series through the average indicator, and determines the efficiency coefficient of each method.
Батуева Светлана Владимировна,

К.n.н., дочент, Южно-Уральский государственный медицинский университет Минздрава России,

2. Челябинск

batuevas@mail.ru

Жакупова Яна Турарована,

К.nсх.н., дочент, Южно-Уральский государственный медицинский университет Минздрава России,

2. Челябинск

ps-gold@yandex.ru

Герасимова Оксана Юрьевна,

К.б.н., дочент, Южно-Уральский государственный медицинский университет Минздрава России,

2. Челябинск

oksana-5858@mail.ru

Семченко Любовь Николаевна,

К.м.н., доцент, Южно-Уральский государственный медицинский университет Минздрава России,

2. Челябинск

luba_sem96@mail.ru

Аннотация: В публикации раскрывается и эмпирически подтверждается влияние театральной студии на уровни социально-личностного развития дошкольников. Определены компоненты социально-личностного развития дошкольников: мотивационно-эмоциональный, коммуникативно-когнитивный и деятельностно-творческий. В качестве критериев выбраны личностные качества, соответствующие каждому компоненту, дана описательная характеристика выбранных качеств. В статье представлены результаты психологического исследования дошкольников и их уровни сформированности социально-личностных качеств ( $n=197$, средний возраст 5,9+0,9 лет), посещающих театральную студию во Дворце пионеров и школьников им. Н.К. Крупской г. Челябинска; детской театральной студии МОУ «СОШ №8» г. Троицка; в городском Доме Культуры и школах искусств №1, №3 г. Троицка; детской театральной студии г. Южноуральска. В работе рассмотрены компоненты с критерии социально-личностного развития у дошкольников и методики их диагностики. Использованы психодиагностические методы исследования: тест тест Розенцвейга (1948), детский апперцептивный тест Леопольда и Сони Беллак (САТ-Н) (1966). Методика исследования волевой готовности тест Бурдона; методики диагностики креативности Гилфрда и Торренса (1962); методика диагностики уровня развития произвольной сферы Н.И. Гуткиной (1981); проективная методика диагностики характера отношений Т.Д. Мирцинковской (1997). Представлены результаты констатирующего эксперимента. На этапе констатирующего эксперимента рассмотрены результаты исследования уровней социально-личностного развития у дошкольников в двух группах: посещающих и не посещающих театральную студию. Проведен анализ количественных результатов, полученных на этапе констатирующего эксперимента. Представлены результаты формирующего эксперимента на примере четырех групп: дошкольники не участвовали в деятельности детской театральной студии; деятельность детской театральной студии осуществлялась по обычной программе; во второй эксперимен- 
Keywords: social and personal development, theater studio, motivationalemotional, communicative-cognitive, activity-creative components, personal qualities of a preschool child. тальной группе проектирование деятельности детской театральной студии осуществлялось частично; В третьей экспериментальной группе осуществлялось проектирование деятельности детской театральной студии в полном объеме. В статье рассмотрена динамика социально-личностного развития дошкольников в деятельности детской театральной студии при помощи динамических рядов через средний показатель, и определен коэффициент эффективности каждой методики.

Ключевые слова: социально-личностное развитие, театральная студия, мотивационно-эмоциональный, коммуникативно-когнитивный, деятельностнотворческий компоненты, личностные качества дошкольника.

\section{Актуальность исследования}

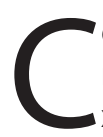
овременные исследования по проблеме личностного развития дошкольника определяют характеристики, которые можно и отнести к универсальным личностным способностям. К данным характеристикам можно отнести: креативность, ответственность, самоценность, самостоятельность, инициативность, организованность. Становление личностных способностей осуществимо в процессе социального развития ребенка. Известно, что процесс социального развития осуществляется в двух направлениях. Первым направлением служит влияния культуры, вторым - усвоение культурного опыта индивидом, актуализацией собственного «Я» через усвоенные культурные ценности и раскрытие творческого личностного потенциала. Ведущим критерием эффективности социального развития выступает не степень усвоения социальных норм и адаптированность к окружающей действительности и проявление индивидуальности личности.

Социально-личностному развитию в онтогенезе, способствует игровая деятельность, в котором ребенок усваивает социальный опыт, проявляет индивидуальность и осознает себя как социально значимый субъект. В процессе игровой деятельности происходит расширение социального пространства ориентация в котором требует личностных качеств, креативность, ответственность, самоценность, самостоятельность, инициативность, организованность. Игровая деятельность способствует развитию физической и психосоциальной области дошкольника. С помощью ролевой игры дошкольник осуществляет практическое применение своих социальных знаний. Уподобляясь героям игры, ребенок развивает способность символической репрезентации и понимая окружающих $[1,4,6]$. В ролевой игре ребенок отслеживает различные поведенческие модели, дает им оценку. Игра позволяет ребенку проявлять свои чувства. Процесс игры данном случае, может быть рассмотрен как отдельный механизм социально-личностного развития, обусловленный действиями подражанием, нормативной регуляцией, присвоением нового опыта [8,7]. Поиск новых форм организации процесса игры и включения ребенка в игровой процесс - это одна из приоритетных психолого-педагогических задач. К эффективной форме организации игрового пространства можно отнести театральные занятия. В процессе совместного проигрывания ролей осваивается социальное пространство, усваивает социальные нормы и ценности [3,2,5]. Исследования показывают, что существуют реальные возможности по организации игровой социально-ориентированной деятельности посредством деятельности детской театральной студии. Театральное искусство объединяет разнообразные выразительные средства, способствующие целостному воздействию на личность. Театральные занятия дают возможность включать ребенка в различные виды игровой деятельности, которые развивают коммуникативные, когнитивные эмоционально и волевые структуры личности ребенка. Однако, исследования по проблеме социально-личностного развития дошкольников посредством театральной деятельности немногочисленны, практических рекомендаций разработано недостаточно. Таким образом, актуальность определяется недостаточностью изученности проблемы социально-личностного развития дошкольников в театральной студии, и практических рекомендаций по данному вопросу.

Целью настоящего исследования является изучение различий в уровнях сформированности личностных качеств и социально-личностного развития у дошкольников посещающих театральную студию и у дошкольников не посещающих театральную студию.

Задачи исследования: 1) определение компонентов и критериев социально-личностного развития у дошкольников; 2) определение уровня сформированности компонентов социально-личностного развития при помощи психолого-диагностического исследования личностных качеств у дошкольников (креативность, ответственность, самоценность, самостоятельность, инициативность, организованность); 3) проведение сравнительного анализа сформированности компонентов социально-личностного развития у дошкольников посещающих и не посещающих театральную студию. 
Организация исследования осуществлялась следующим образом. В результате теоретического анализа были определены компоненты и критерии социальноличностного развития дошкольников. К компонентам социально-личностного развития дошкольника были отнесеныследующие:мотивационно-эмоциональный, коммуникативно-когнитивный, деятельностно-творческий. Критериями каждого компонента явились личностные качества: мотивационно-эмоциональный - (ответственность, самостоятельность), коммуникативно-когнитивный - (инициативность, самоценность), деятельностнотворческий (креативность, организованность).

Каждый из компонентов оценивался по нескольким тестам (для высокой достоверности) и был разделен на три уровня сформированности: компонент отсутствует или проявлен недостаточно (низкий уровень), компонент проявлен (средний уровень), компонент развит (высокий уровень).

На констатирующем этапе при помощи психодиагностических методик, были определены уровни сформированности социально-личностных качеств у дошкольников, посещающих и не посещающих театральную студию.

На формирующем этапе эксперимента была внедрена комплексная программа театральной студии, направленная на развитие социально-личностных качеств у дошкольников. Были созданы экспериментальные группы, имеющие изначально равные параметры, но в которых осуществлялось социокультурное проектирование, опирающееся на различное содержание. Целостная комплексная программа полностью внедрялась в одной экспериментальной группе - ЭГ-3. В ЭГ-1 деятельность детской театральной студии осуществлялась без внедрения комплексной программы театральной студии. В ЭГ- 2 осуществлялось Внедрение комплексной программы детской театральной студии, однако в содержательной части: комплексной программы, отсутствовало одно из направлений - развитие мотивационно-эмоционального компонента. В КГ занятия в театральной студии не осуществлялись.

На обобщающем этапе эксперимента осуществлялась аналитическая деятельность. Были определены различия в экспериментальные и контрольные группы осуществлялась следующим образом: анализ количественных характеристик каждой группы; количественная оценка уровня социально-личностного развития и определение коэффициента эффективности каждой методики; определение и представление абсолютного прироста среднего показателя в экспериментальных и контрольной группах. Определение достоверности различий осуществлялась при помощи Критерия Пирсона.

\section{Методы исследования}

Для реализации цели и задач исследования был использован психодиагностический комплекс, включавший проективные методики для исследования индивидуальных особенностей и качеств личности дошкольника: тест Розенцвейга (1948), детский апперцептивный тест Леопольда и Сони Беллак (САТ-Н) (1966). Методика исследования волевой готовности тест Бурдона; методики диагностики креативности Гилфрда и Торренса (1962); методика диагностики уровня развития произвольной сферы Н.И. Гуткиной (1981); проективная методика диагностики характера отношений Т.Д. Мирцинковской $(1997)[9,10]$.

Математико-статистическая обработка исследование динамики процесса социально-личностного развития осуществлялось определением коэффициента эффективности каждой методики при помощи динамических рядов. Определением и представлением абсолютного прироста среднего показателя в экспериментальных и контрольной группах. А также критерия $\chi^{2}$ Пирсона (для номинативных признаков). Полученные результаты были обработаны с использованием стандартных методов математической статистики, включенных в статистические пакеты SPSS 20.0

Материал исследования составили личностные характеристики 197 дошкольников: ответственность, самостоятельность, инициативность, самоценность, креативность, организованность, средний возраст дошкольников составил 5,9+0,9 лет.

Результаты исследования с помощью психодиагностического комплекса исследований. При помощи психодиагностических методов были определены уровни сформированности социально-личностного в ЭГ-1, ЭГ-2, ЭГ- 3, в начале и в конце эксперимента. Исследуемые характеристики и результаты исследования приведены в таблице 1.

Результаты исследования позволили сделать предположение, что театральная студия способствует социальному развитию с дошкольника, это утверждение доказывают следующие показатели: ЭГ-1, где дети посещали театральную студию, показатели социально-личностного развития выше, чем показатели КГ, где дети не посещали театральную студию. В ЭГ-2 показатели социальноличностного развития выше, чем показатели КГ, где дети не посещали театральную студию. Однако, при внедрении комплексной программы в полной мере, осуществляется повышение профессиональной компетентности педагогов - художественных руководителей ЭГ-3, значительно повышается эффективность социально-личностного развития дошкольников. 
Таблица 1.

Результаты диагностики сформированности социально-личностного развития дошкольников в детской театральной студии

\begin{tabular}{|c|c|c|c|c|c|c|c|c|c|}
\hline \multirow{3}{*}{ Группа } & \multirow{3}{*}{ Этап } & \multicolumn{6}{|c|}{ Уровни } & \multirow{3}{*}{$C p$} & \multirow{3}{*}{$K_{\ni \phi \phi}$} \\
\hline & & \multicolumn{2}{|c|}{ низкий } & \multicolumn{2}{|c|}{ средний } & \multicolumn{2}{|c|}{ Высокий } & & \\
\hline & & Кол-во & $\%$ & Кол-во & $\%$ & Кол-во & $\%$ & & \\
\hline \multirow{2}{*}{$Э Г-1$} & начало & 26 & 80 & 5 & 16 & 2 & 4 & 1.13 & 1.64 \\
\hline & конец & 9 & 28 & 16 & 51 & 8 & 21 & 1.45 & 0.81 \\
\hline \multirow{2}{*}{$Э Г-2$} & начало & 26 & 76 & 6 & 17 & 2 & 7 & 1.31 & 0.74 \\
\hline & конец & 7 & 22 & 16 & 48 & 11 & 30 & 2.08 & 1.16 \\
\hline \multirow{2}{*}{$Э Г-3$} & начало & 20 & 68 & 6 & 22 & 4 & 10 & 1.42 & 0.8 \\
\hline & конец & 1 & 2 & 11 & 35 & 18 & 63 & 2.61 & 1.46 \\
\hline \multirow{2}{*}{ КГ } & начало & 39 & 39 & 46 & 46 & 15 & 15 & 1.76 & - \\
\hline & конец & 36 & 36 & 49 & 49 & 15 & 15 & 1.79 & - \\
\hline
\end{tabular}

Исследование динамики процесса социально-личностного развития дошкольников в театральной студии осуществлялось с применением следующих динамических рядов:

- средний показатель (Cp), отражающий количественную оценку роста уровня сформированности социально-личностного развития, который был вычислен по формуле:

$$
C p=\frac{1 a+2 b+3 c}{100},
$$

где $a, b, c$ - выраженное в процентах количество детей, находящихся на высоком, среднем и низком уровнях сформированности социально-личностного развития. Цифры «1», «2», «3»- это весовые коэффициенты уровня. Коэффициент эффективности экспериментальной методики, который вычисляется по формуле: $\mathrm{K}_{э \phi \phi}=\mathrm{Cp}(э) / C p(\kappa)$, где Сp(э) - значение среднего показателя экспериментальной группы; Ср(к) - значение среднего показателя контрольной группы.

Показатель абсолютного прироста (G), отражающий разность начального и конечного значений уровня (или отдельного критерия, показателя) социально-личностного развития у дошкольников, посещающих детскую театральную студию, который вычисляется по формуле:G $=\Pi_{\text {кон }}-\Pi_{\text {нач' }}$ где $\Pi_{\text {нач }}-$ начальное значение уровня; $\Pi_{\text {кон }}$ - конечное значение уровня. Результаты исследование представлены в таблице 2.

Представленная в таблице динамика уровней социально-личностного развития дошкольников в студии в экспериментальных и контрольной группах показывает, что в ЭГ-3, где осуществлялось действие программы деятельности детской студии по социально-личностному развитию в полной мере, прирост высокого уровня сформированности социально-личностного развития составил - 53\%. В ЭГ-2, где осуществлялось внедрение программы для детей, но не осуществлялось повышение профессиональной компетентности педагогов, работающих в театральной студии, прирост высокого уровня социально-личностного развития составил - 23 \%. В ЭГ1, где были дети, посещающие театральную студию без внедрения программы, прирост высокого уровня составил - 16\%. В КГ прирост высокого уровня не произошел. Одновременно снизилось количество дошкольников на низком уровне в ЭГ-1 до 28\%, в ЭГ-2 до $22 \%$ в Э ЭГ-3 - до 2 \%, в КГ до 36\%. В контрольной группе, ЭГ-1 и ЭГ-2, по результатам контрольного среза у большинства дошкольников определен на средний уровень сформированности социально-личностного развития, в ЭГ-3 -на среднем уровне 35 -\% и 63 \% определен высокий уровень.

Проверка достоверности гипотезы проводилась по критерию согласия ұ2 Пирсона, который позволяет установить эффективность эксперимента.. Результаты представлены в таблице 3.

Для уровней статистические значимые отличия зафиксированы, а уровне значимости. Так как эмпириче-

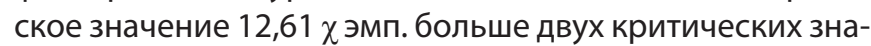
чений, то Н0 гипотеза будет отвергнута. Таким образом, уровень сформированности социально-личностных качеств в ЭГ-3, где осуществлялось внедрение программы деятельности театральной студии, в полной мере отличается от уровня сформированности в КГ, это свидетельствует об эффективности программы театральной студии,

\section{Зак^ючение}

Настоящее исследование посвящено изучению социально-личностного развития дошкольников в деятельности театральной студии. Изучен широкий спектр личностных характеристик у дошкольников. Сравнительный анализ контрольной и экспериментальных групп позволил сделать выводы: разница в результатах экспериментальных и контрольных групп свидетель- 
Таблица 2.

Динамика уровней социально-личностного развития дошкольников театральной студии

\begin{tabular}{|c|c|c|c|c|c|}
\hline \multirow{3}{*}{ Группа } & \multicolumn{5}{|c|}{ Показатели абсолютного прироста (G) } \\
\hline & \multicolumn{3}{|c|}{ G по уровням (в \%) } & \multirow{2}{*}{$\mathrm{G} п \mathbf{C} \mathrm{p}$} & \multirow{2}{*}{$\mathrm{G}$ по $\mathrm{K}_{\ni \phi \phi}$} \\
\hline & низкий & средний & высокий & & \\
\hline$Э Г-1$ & -52 & 35 & 16 & 0.66 & 0.83 \\
\hline ЭГ-2 & -54 & 31 & 23 & 0.77 & 0.42 \\
\hline$Э Г-3$ & -66 & 13 & 53 & 1.19 & 0.96 \\
\hline KГ & -3 & 3 & 0 & 0.03 & - \\
\hline
\end{tabular}

Показатели различий в уровнях в ЭГ 1, ЭГ 2, ЭГ 3 и КГ

\begin{tabular}{|c|c|c|c|}
\hline Группа & $\chi_{\text {наб }}^{2}$ & $\chi_{\text {наб }}^{2} \chi_{\text {коит }}^{2}$ & Статистическая 3начимость \\
\hline ЭГ- и КГ & 0,148 & $0,148<5,991$ & статистически не 3начимо \\
\hline ЭГ-2 и КГ & 0,1642 & $0,1642<5,991$ & статистически не 3начимо \\
\hline ЭГ-3 и КГ & 12,61 & $12,61>5,991$ & статистически значимо \\
\hline Для $d f=2$ и $\alpha=0,05 \chi_{\text {крит }}^{2}=5,991$ & \\
\hline
\end{tabular}

ствует о том, что социально-личностное развитие дошкольников идет успешней при внедрении программы детской театральной студии по социально-личностному развитию дошкольников. Для практического применения педагогов-психологов следует отметить, что дея- тельность в театральной студии при применении комплексной программы, ориентированной на развитие социально-личностных качеств ребенка, посещающего театральную студию, способствует успешному социально-личностному развитию.

\section{ЛИТЕРАТУРА}

1. Абраменкова В.В. А Социальная психология детства: Учебное пособие / В.В Абраменкова- М.: ПЕР (Э, 2008. — 431 с.

2. Выготский, Л.С. Педагогическая психология / Л.С. Выготский. - М.: Педагогика, 1991. - 420 с.

3. Бодалев, А.А. Личность и общение: избр. психол. тр. / А.А. Бодалев. - М.: Междунар. пед. академия, 1995. - 328 с.

4. Божович, Л.И. Личность и ее формирование в детском возрасте / Л.И. Божович. - М.: Просвещение, 1968. - 584 с

5. Голованова, Н.Ф. Социализация и воспитание ребенка / Н.Ф. Голованова.- СПб.: Речь, 2004.-272 с.

6. Круглова, Л.Ю. Развитие творческих способностей ребенка дошкольного и младшего школьного возраста в системе дополнительного образования: метод. пособие / Л.Ю. Круглова. - М.: Полицентр, 2005. - 117 с.

7. Крулехт, М.В. Дошкольник и рукотворный мир: педагогическая технология целостного развития ребенка как субъекта детской деятельности / М.В. Крулехт. - СПб, 2002.

8. Петровский, А.В. Проблемы развития личности с позиций социальной психологии / А.В. Петровский // Вопросы психологии, 1984.- №4.- С. 11-29.

9. Шевченко, Маргарита Психологические рисуночные тесты для детей и взрослых / Маргарита Шевченко. - М.: АСТ, 2014. - 675

10. Энциклопедия психодиагностики. Психодиагностики детей. Смамара: Издательский дом «Бахрах - М», 2014. - 624 с. 